\title{
EFFECTS OF ALUMINUM COMPOSITES ON THE REGRESSION RATES OF SOLID FUELS
}

\section{Paravan, S. Penazzo, S. Dossi, M. Stocco, L. T. DeLuca, and L. Galfetti}

Politecnico di Milano, Aerospace Science and Technology Department

Space Propulsion Laboratory (SPLab)

Milano 20156, Italy

Innovative, mechanically activated Al-polytetrafluoroethylene (PTFE) composites and ammonium perchlorate (AP) coated nano-sized aluminum (C-ALEX) were produced, characterized, and tested as solid fuel additives. The ballistics of fuel formulations based on hydroxylterminated polybutadiene (HTPB) was investigated in a microburner by a time-resolved technique for regression rate $\left(r_{f}\right)$ data reduction. Both Al-composites show promising results in terms of $r_{f}$ and mass burning rate enhancement. In particular, the C-ALEX showed a percent $r_{f}$ increase over the baseline (HTPB) of $27 \%$ at an oxidizer mass flux of $350 \mathrm{~kg} /\left(\mathrm{m}^{2} \mathrm{~s}\right)$, without requiring dedicated dispersion procedures. This performance enhancement was nearly constant over the whole investigated range.

\section{NOMENCLATURE}

a multiplicative factor (Eqs. (2) and (5))

$a_{s} \quad S_{\mathrm{sp}}$-derived particle diameter, $\mathrm{nm}$

Act-Al15 $(X)$ mechanically activated Al15 $+X \%$ (wt.) PTFE

ALEX aluminum exploded (air-passivated nAl produced by EEW)

Al15 spherical micron-sized aluminum with particle size of $15 \mu \mathrm{m}$

AP ammonium perchlorate

C-ALEX $(X)$ AP-coated ALEX, $X \%$ (wt.) coating

$D \quad$ port diameter, $\mathrm{mm}$

$\bar{D}_{i} \quad i$ th sampled space-averaged port diameter, $\mathrm{mm}$

EEW electrical explosion of wire

fps frames per second

G mass flux, $\mathrm{kg} /\left(\mathrm{m}^{2} \mathrm{~s}\right)$

GOx gaseous oxygen 


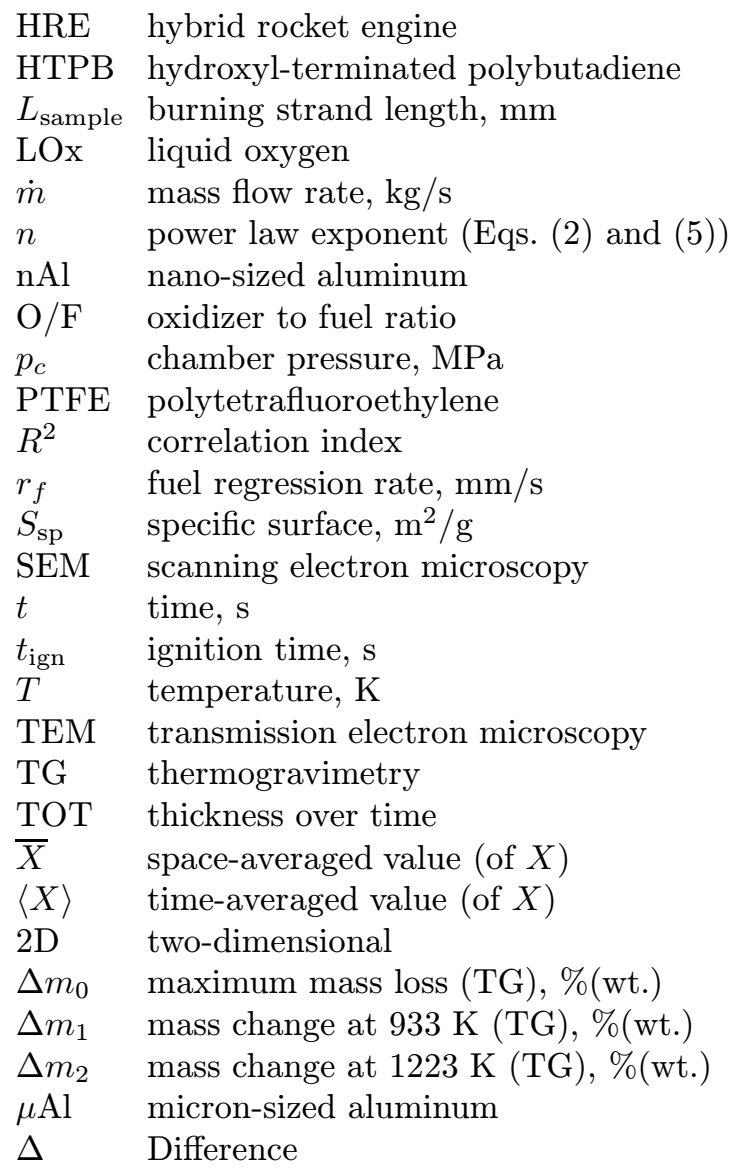

\section{Subscripts}

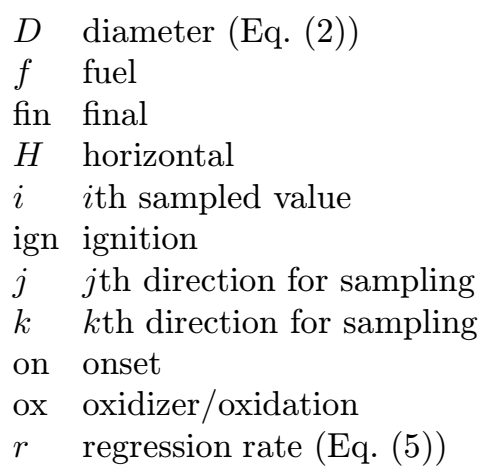


$s$ surface

$v$ vertical

0 reference condition

$\%$ percent value

\section{INTRODUCTION}

In a hybrid rocket engine (HRE), the fuel and the oxidizer are stored in different states of matter. In the most commonly implemented and investigated configurations (direct hybrid), the oxidizer is liquid (or gaseous) while the fuel is solid. In a direct hybrid, the combustion can take place only when the oxidizer flows over the solid fuel grain. The resulting diffusion flame is established in the boundary layer [1]. The heat feedback from the flame to the grain sustains the fuel gasification, yielding the condensed fuel surface regression. When compared to mature liquid rocket engines and solid propellant motors, HREs offer interesting features as high operating flexibility and theoretical performance, increased safety, and reduced recurring costs [1]. In particular, the maximum theoretical specific impulse of HREs based on liquid oxygen (LOx)-HTPB is close to the one of LOx-hydrocarbon liquid propellants [1]. In spite of this, the use of the hybrid configuration in operating missions is hampered by HREs low $r_{f}$ and combustion efficiency. Both of these drawbacks of hybrid systems are related to the diffusive nature of the flame ruling the combustion process $[1,2]$. The limits of low $r_{f}$ (and $\dot{m}_{f}$ ) and of the poor combustion efficiency hinders HRE implementation in high-thrust applications (i.e., launch systems) and in-space missions (where high effective specific impulse is required to minimize launched masses).

This work focuses on the ballistics of HTPB-based fuel formulations loaded with Al-based composite additives. The metal composites are designed and developed to promote the ballistic performance of HRE fuel formulations in terms of $r_{f}\left(\right.$ and $\left.\dot{m}_{f}\right)$. The energetic additives were created by mechanical and chemical activation processes aiming at depositing an oxidizing species source (i. e., PTFE, AP) over the surface of an energetic fuel powder (i. e., Al). The oxidizing species deposition was executed by mechanical activation for Al-PTFE additives, while a chemical approach yielded to the Al-AP powders. The strategy driving the composite formulation and realization is based on the reduced diffusion distances between the fuel $(\mathrm{Al})$ and the oxidizing species sources (PTFE, AP) aiming at enhancing the composite reactivity. In HRE combustion, the fuel diffusion in the reacting boundary layer dominates the heat feedback to the regressing surface. The use of Al-PTFE and Al-AP is a way to overcome this limiting process by yielding oxidizing species close to the metal particles and to the gasifying surface. This should promote the heat feedback to the condensed phase. Differently from approaches where the oxidizer (usually, AP) is added as a powder in the solid 
fuel matrix, the presented strategy places a limited amount of oxidizer as close as possible to the energetic fuel (i. e., $\mathrm{Al}$ ) with the aim of maximizing the composite effects on $r_{f}$, while limiting the influence on solid fuel grain intrinsic safety and exhaust composition.

The produced composites were characterized in terms of their particle size distribution, morphology, active metal content, and ignition temperature. The ballistic response of the investigated fuel formulations is analyzed by a timeresolved technique for $r_{f}$ data reduction. The solid fuel ballistics characterization is performed considering the effects of the additives on the formulations $r_{f}$ and $\dot{m}_{f}$. Cured HTPB was taken as the baseline fuel for the relative ballistic grading of the tested composite-loaded formulations.

\section{LITERATURE SURVEY}

In direct HREs, the flame zone is established in the boundary layer developed by the oxidizer flow over the solid fuel grain. Fundamentals of turbulent combustion in the boundary layer are discussed in [3-5]. Under the hypothesis of exclusive convective heat transfer from the flame to the regressing surface, the model developed by Marxman and Gilbert [3] shows $r_{f} \propto G^{0.8}(x)$, with $G(x)=G_{\text {ox }}$ $+G_{f}(x)$. The influence of $p_{c}$ on the solid fuel $r_{f}$ is widely discussed in the literature, though a unique behavior cannot be identified [2-8]. A detailed survey of studies about $p_{c}$ influence on solid fuel $r_{f}$ is given by Chiaverini [2].

The relatively low $r_{f}$ of hybrid fuel formulations is usually considered as the main drawback of these systems, since HREs are usually considered for access-tospace systems where high-thrust requirements drive the design. Techniques for $r_{f}$ enhancement include solid fuel loading with energetic additives [9], entrainment of melt fuel droplets $[10,11]$, and the implementation of nonconventional oxidizer flow injections $[12,13]$.

In spite of significant $r_{f}$ increase (3-4 times faster than the conventional fuels), entrainment-producing fuels (e.g., paraffin waxes) usually exhibit poor mechanical properties [14]. This limits their possible applications in large-scale systems. In spite of their effective $r_{f}$ enhancements at lab-scale level or in smallthrust systems $[12,13]$, exotic oxidizer flow inlet configurations, as vortex flow and swirl injections, could be ineffective on intermediate and large-scale motors due to the viscous dumping of tangential components of the flow velocity. Solid fuel loading with energetic additives offers possible performance enhancements while granting overall fuel grain mechanical properties. Moreover, this approach can be implemented for small- as well as for large-scale systems.

Energetic additives for the solid fuel loading include metal or oxidizer powders and hydrides $[9,15]$. Ballistics of HTPB-based formulations loaded with AP was investigated in details by George et al. [16] and Frederick et al. [17]. 
The fuel grain loading with oxidizer particles provides significant performance enhancements. Considering HTPB $+25 \%$ (wt.) AP burning in gaseous oxygen $(\mathrm{GOx})$ with $G_{\mathrm{ox}}=160 \mathrm{~kg} /\left(\mathrm{m}^{2} \mathrm{~s}\right)$, a percent $r_{f}$ increase of $200 \%$ with respect to pure HTPB can be achieved [17]. On the other hand, while granting a significant ballistic performance enhancement, the solid fuel grain loading with high mass fractions of oxidizing powders hinders the advantage of improved safety and $\mathrm{HCl}$-free emissions of conventional direct hybrid systems. Hydrides are attractive energetic additives for fuel formulations performance enhancement [18-20]. Nevertheless, these materials exhibit high chemical reactivity with commonly employed binders as HTPB [21,22].

Recently, studies on hydride effects on paraffin-based fuel ballistics have been conducted by Larson et al. [22] and DeSain et al. [23]. First studies on metal-loaded fuel formulation for $r_{f}$ enhancement date back to the 1960s [9]. In this early investigations, the tested metal additive particle sizes were in the micron-size range; thus, the achieved $r_{f}$ increases were mainly due to the augmented radiation heat flux from the flame zone to solid fuel surface [9]. Conventional micron-sized additives are characterized by $S_{\mathrm{sp}} \leq 1 \mathrm{~m}^{2} / \mathrm{g}$, hindering their combustion close to the regressing surface. This limits their contribution to the $r_{f}$ enhancement. Nonisothermal oxidation studies (differential scanning calorimetry / differential thermal analysis - thermogravimetry (TG)) reveal that only minor mass increases are achieved by $\mu \mathrm{Al}$ for temperatures $<1200 \mathrm{~K}[24]$. The reactivity of conventional micronsized additives can be enhanced by activation processes [25-28], or by nano-sized powders $[7,29,30]$. Nonconventional micron-sized additives include composite [31] and activated [32] materials. In the first case, the additive reactivity is tailored by a dedicated synthesis or coating process. As a result, the final product exhibits increased reactivity usually testified by a lower oxidation onset temperature or ignition temperature [31].

Activation processes can be classified into mechanical, chemical, and mechanochemical approaches. In the first case, a single or a combination of additives (usually, both in the micron-sized range) are treated by a mechanical milling process. The resulting composite powder exhibits a combination of the characteristics of the starting ingredients offering the possibility of tailored reactivity and overall features. With this approach, as a consequence of the applied mechanical stresses, the final product $S_{\mathrm{sp}}$ can be increased with respect to the starting materials. Sippel et al. [32] enhanced the reactivity of $\mu \mathrm{Al}$ (Valimet H30, mean particle size of $35 \mu \mathrm{m}$ ) by mechanical activation with PTFE (mean particle size of $35 \mu \mathrm{m}$ ). Under nonisothermal oxidation in $\mathrm{Ar}-\mathrm{O}_{2}$, the activated powder exhibits a distinguishing behavior with respect to the simple mix of the two ingredients. In particular, the activated $\mu \mathrm{Al} / \mathrm{PTFE}$ exhibits exothermic reactions below the aluminum melting temperature $(933 \mathrm{~K})$. A review of the mechanical milling effects on the characteristics and thermal/combustion behaviors of the final products is reported in [33]. The chemical approach for the 
activation of energetic materials $[25,26]$ is based on a chemical modification of the virgin material composition/characteristics (e. g., particle surface functionalization). The mechanochemical activated materials exploit a combination of the mechanical and chemical approaches [34], chemical reactions being promoted by the milling environment/process. Nano-sized particles exhibit enhanced reactivity with respect to conventional, coarser particles, as testified by simultaneous thermal analysis [35] and burning tests $[9,29,36]$.

Thanks to their reduced size, nanoparticles exhibit high $S_{\mathrm{sp}}\left(\sim 10 \mathrm{~m}^{2} / \mathrm{g}\right)$, in turn yielding a high reactivity possibly favoring the energy release close to the energetic material regressing surface. Thus, nanomaterials may result effective for $r_{f}$ enhancement (at least under certain experimental conditions) [29, 3739]. On the other hand, nanoparticles require proper dispersion techniques to contrast/limit cold cohesion/clustering of particles. Though no detailed study on this aspect is available in the open literature, additive dispersion is considered crucial in order to be effective in ballistic performance enhancement $[37,40]$. Due to their enhanced reactivity, nano-sized particles can exhibit a high sensitivity to ageing processes [41]. In spite of this, few open-literature studies deal with ageing of nanometric energetic materials [42-44].

Contrasting the nano-sized additive characteristics with those of activated micron-sized metal powders, some advantages of the latter arise. Activated micron-sized materials offer a larger size than the nanometric counterpart. In general, this implies a higher active metal content (i.e., higher energy content) and a smaller $S_{\mathrm{sp}}$ that is in between the one of the conventional materials and that of nano-sized additives. The reduced $S_{\mathrm{sp}}$ could yield positive effects on the viscosity of the activated particle suspension during solid fuel manufacturing, while limiting the impact of ageing effects of these powders.

\section{STRATEGY AND INVESTIGATED MATERIALS}

In this section, the characteristics of the investigated additives and the details of the fuel manufacturing procedure are discussed. This work investigates metaloxidizer composite energetic additives for the performance enhancement of solid fuel formulations for hybrid combustion. The metal-based composites enable the solid fuel loading with small (and localized) amounts of oxidizer. The composite powders should yield benefits to the solid fuel ballistic response thanks to the oxidizer availability close to the metal particles during their ignition and combustion.

The considered energetic materials are characterized in terms of their particle size, morphology, active metal content, and reactivity. The powder particle size was determined by laser diffraction (Malvern Mastersizer 2000) or nitrogen desorption (deriving the particle radius from the $S_{\mathrm{sp}}[45]$ ). The particles 
morphology was investigated by optical microscopy and by scanning electron microscopy (SEM). The additives metal content was determined by a volumetric method based on the $\mathrm{Al}+\mathrm{H}_{2} \mathrm{O}$ reaction [45]. The additive reactivity is evaluated by oxidation, monitoring the sample weight during heating (TG), and by the ignition temperature tests performed by a hot-wire technique [46]. In the TG analyses, the relative grading of the powder reactivity is performed considering the parameters identified by Ilyin et al. [47]. The nonisothermal oxidation tests are performed in air, with a heating rate of $10 \mathrm{~K} / \mathrm{min}$. The ignition temperature of the composites was investigated under ambient conditions (air, $0.1 \mathrm{MPa}$ ), with a heating rate of $250 \pm 50 \mathrm{~K} / \mathrm{s}$.

\subsection{Aluminum-Based Composites: Production and Characterization}

This section provides a description of the production procedures of the investigated composites and of their characteristics. In this study, two different families of aluminum-based additives are considered. In the first one, an $\mathrm{Al}$ powder with nominal size of $15 \mu \mathrm{m}$ (Al15) was used. The second family of energetic additives is manufactured from an ALEX powder with nominal size of $100 \mathrm{~nm}$ (ALEX100). Figure 1 shows optical and electron microscope images of Al15 and ALEX. Details on the Al15 particle size distribution are given in Table 1. The Al15 particles have a spherical shape, with an apparently smooth texture. The monomodal particle size distribution yields $D_{43}=19.8 \mu \mathrm{m}$. The powder $C_{\mathrm{Al}}$ is $(99.5 \pm 0.4) \%$ (wt.). The ALEX is produced by electrical explosion of wire (EEW) and is passivated by air. The as-received nano-sized particles are coated by cat-

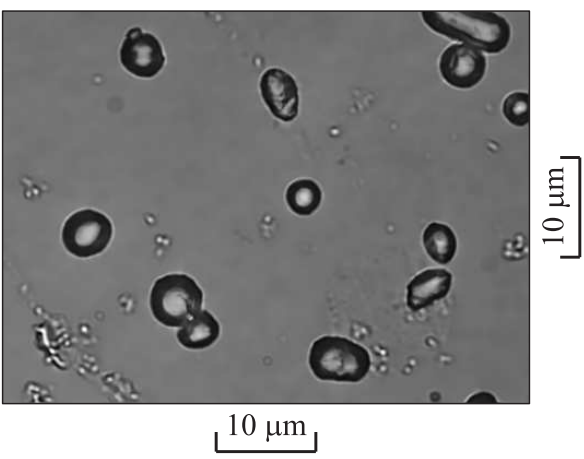

(a)

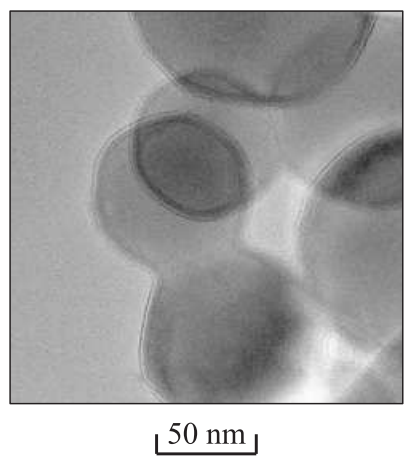

(b)

Figure 1 Virgin powders used for the aluminum-based composites: $(a)$ optical microscope image of the virgin Al15; and (b) SEM micrograph of ALEX100 
Table 1 Particle size distribution, mean surface, mass-based diameters (as evaluated by laser diffraction), and active aluminum content of the investigated virgin powders and composites. Size data are evaluated by laser diffraction, considering smooth spherical particles. Since Act-Al15 and C-ALEX powders show irregular shape and texture, their size distributions should be considered only for activated-additive relative grading

\begin{tabular}{lccccccc}
\hline \multirow{2}{*}{ Powder Id. } & $\begin{array}{c}D_{32}, \\
\mu \mathrm{m}\end{array}$ & $\begin{array}{c}D_{43}, \\
\mu \mathrm{m}\end{array}$ & $\begin{array}{c}D_{(0.1)}, \\
\mu \mathrm{m}\end{array}$ & $\begin{array}{c}D_{(0.5)}, \\
\mu \mathrm{m}\end{array}$ & $\begin{array}{c}D_{(0.9)}, \\
\mu \mathrm{m}\end{array}$ & Span & $C_{\mathrm{Al}}, \%$ (wt.) \\
\hline PTFE $^{a}$ & 0.75 & 7.24 & 0.36 & 0.88 & 8.28 & 8.98 & - \\
Al15 & 16.3 & 19.8 & 10.0 & 17.9 & 32.3 & 1.24 & $99.5 \pm 0.4$ \\
Act-Al15 & 38.0 & 123 & 15.9 & 90.8 & 284 & 2.96 & $98.2 \pm 0.1$ \\
Act-Al15(10) & 20.1 & 28.4 & 12.0 & 25.1 & 49.5 & 1.49 & $90.5 \pm 0.1$ \\
Act-Al15(30) & 9.48 & 31.2 & 5.46 & 21.7 & 59.4 & 2.49 & $68.6 \pm 0.6$ \\
\hline C-ALEX(10) & 1.07 & 6.50 & 0.43 & 2.02 & 18.7 & 9.06 & $80.5 \pm 2.0$ \\
C-ALEX(15) & 1.00 & 6.73 & 0.42 & 1.66 & 16.0 & 9.53 & $74.8 \pm 1.3$ \\
\hline${ }^{a}$ See Ref. [48]. & & & & & & &
\end{tabular}

echol $\left(0.2 \%\right.$ (wt.)). The ALEX100 exhibits $S_{\mathrm{sp}}=10.7 \mathrm{~m}^{2} / \mathrm{g}$, in turn yielding $a_{s}=208 \mathrm{~nm}$, and $C_{\mathrm{Al}}=(88 \pm 0.3) \%$ (wt.). The micrometric aluminum is used as the base ingredient in Al-PTFE composites obtained by mechanical activation process. The nano-sized aluminum is coated by AP, yielding to a fuel-oxidizer composite material produced by chemical activation. The PTFE and AP mass fractions in the composites are heuristically selected, with the driver of a reduced overall oxidizer content $(<5 \%$ (wt.)) in the final fuel grain.

\subsubsection{Mechanically activated micron-sized aluminum}

The Al15 is activated by a low-energy mechanical process. The activation is performed by a centrifugal mill, with alternate clockwise-counter clockwise rotation. A bimodal distribution of stainless steel spheres was used to achieve a ball to powder ratio of $5: 1$. The process controlling agent was toluene $(0.2 \%$ (wt.) of the powder charge). The activation atmosphere was air and it was not controlled in temperature.

The mechanical activation was performed on Al15 and Al15 + PTFE mixtures. The Al-fluoropolymer mixtures were homogenized by a resonant acoustic mixer (Resodyn ${ }^{\mathrm{TM}}$ LabRam Mixer [49]) before the milling process. The fluoropolymer was in a dry disperse phase (mean particle size of $1 \mu \mathrm{m}$ ). Three activated composites are considered in this study. The Act-Al15 is the product of mechanical milling applied to the virgin Al15 without the addition of PTFE. The Act-Al15(10) and the Act-Al15(30) are the powders produced by the milling process applied to $\mathrm{Al}+\mathrm{PTFE}$ mixtures with a fluoropolymer mass fraction of $10 \%$ and $30 \%$, respectively. 


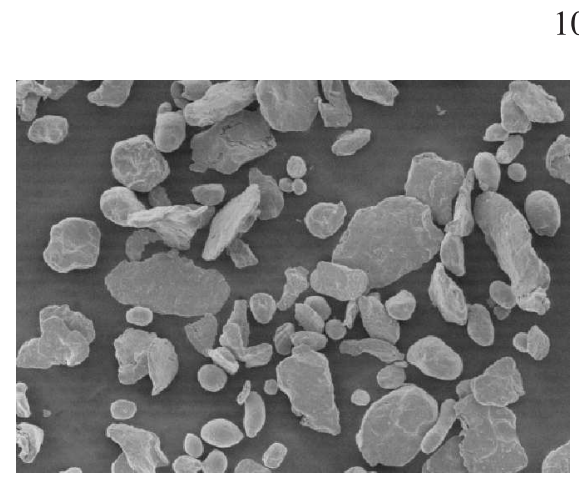

(a)

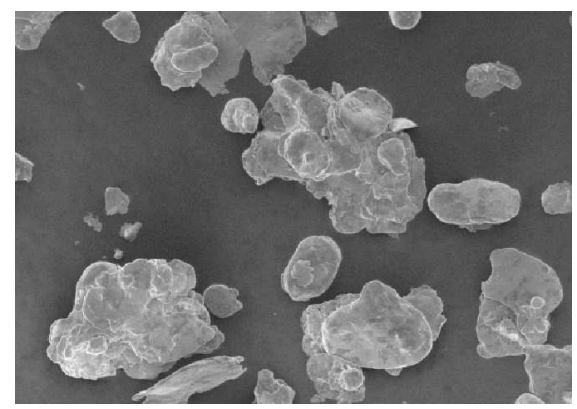

(c)
$10 \mu \mathrm{m}$

$\longrightarrow$

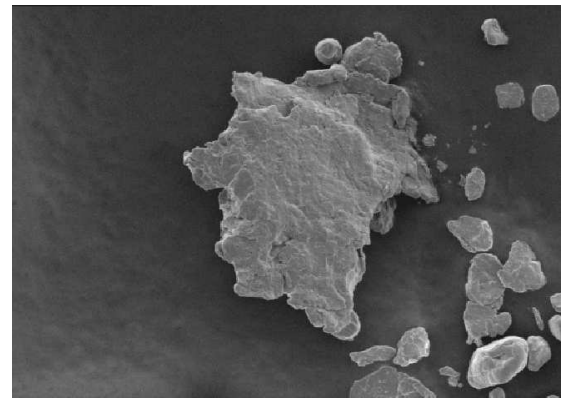

(b)

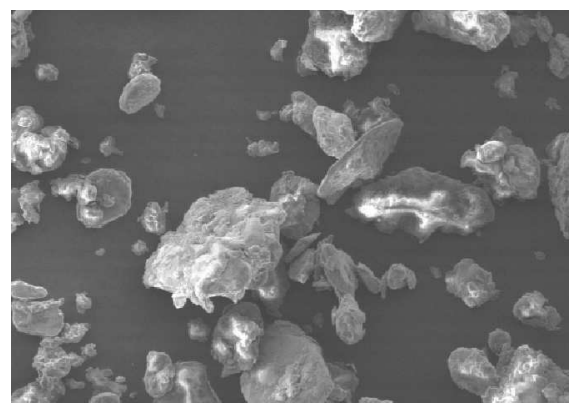

(d)

Figure 2 The SEM images of Act-Al: $(a)$ and (b) Act-Al15; (c) Act-Al15(10); and (d) Act-Al15(30)

Figure 2 shows the particle morphology after the activation process for the investigated additives, while other relevant size distribution and $C_{\mathrm{Al}}$ data are reported in Table 1. The Act-Al15 SEM images presented in Fig. $2 a$ show irregularly shaped particles. The shape alteration is induced by the milling process. Aluminum flakes with a rough surface texture can be recognized (Fig. 2b), though some particles with nearly spherical shape are still present in the additive. The Al flakes can be originated by the direct sphere-particle collisions, or by sphere-multiple particles impacts.

According to the achieved particle size characterization data, Act-Al15 powder presents a bimodal size distribution, with peaks at 25 and $115 \mu \mathrm{m}$ (Fig. 3). Under the considered operating conditions, a small particle fraction $(\sim 1 \%$ (vol. $))$ exhibits a particle size in the range 1 to $5 \mu \mathrm{m}$ and probably results from the particle fragmentation due to the milling process. In spite of the presence of nearly-spherical objects, the particle size distribution of the Act-Al15 is significantly altered with respect to the virgin material case. So is its reactivity as 


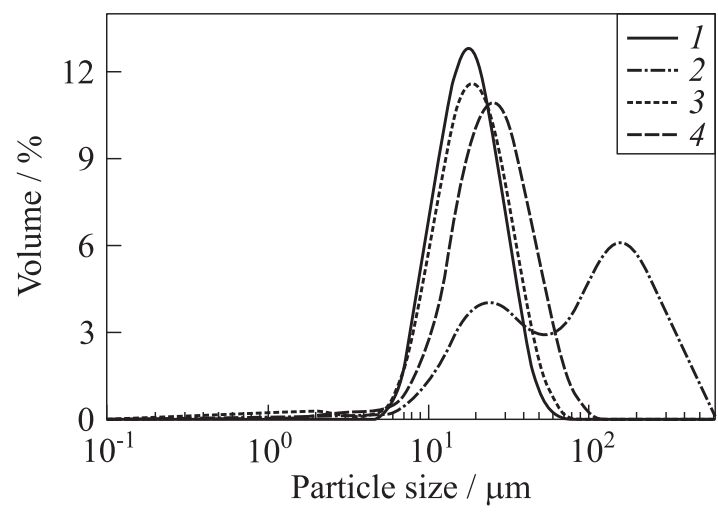

Figure 3 Particle size distribution by laser diffraction of the virgin Al15 (1), ActAl15 (2), mechanically mixed (no milling activation) Al15 + 10\%(wt.) PTFE (3), and Act-Al15(10) (4). Data reduction algorithm considers spherical and smooth-texture particles, while Act-Al15 and Act-Al15(10) particles show irregular shape and texture

testified by the data reported in Tables 2 and 3. In particular, under slow heating oxidation conditions, the Act-Al15 exhibits $\Delta m_{1}=4.1 \%$ and $\Delta m_{2}=9.1 \%$, with enhanced performance with respect to the Al15. The Act-Al15 exhibits no mass loss during heating in the nonisothermal oxidation tests (i. e., no adsorbed species desorption was sensed by the TG). This evidence suggests a limited impact of the mechanical activation process on the powder $S_{\mathrm{sp}}$, since materials with high specific surface area usually show a $1 \%-2 \%$ mass desorption during heating.

The effect of the milling process on the Al15 is in any case visible as a shape and texture alteration, with the presence of (few) nonmilled particles. The Act-

Table 2 Reactivity parameters for nonisothermal oxidation in air (TG in air, heating rate $10 \mathrm{~K} / \mathrm{min}$ )

\begin{tabular}{lcccc}
\hline \multicolumn{1}{c}{ Powder Id. } & $\Delta m_{0}, \%$ (wt.) & $T_{\text {on }, 1}, \mathrm{~K}$ & $\Delta m_{1}, \%$ (wt.) & $\Delta m_{2}, \%$ (wt.) \\
\hline Al15 & 0 & 845 & 0.8 & 5.0 \\
Act-Al15 & 0 & 840 & 4.1 & 9.1 \\
Act-Al15(10) & -7.1 & 899 & -5.2 & 0.3 \\
Act-Al15(30) & -24.1 & 902 & -23.6 & -21.1 \\
\hline ALEX & -1.3 & 842 & 27.1 & $60.8^{a}$ \\
C-ALEX (15) & $-14.1^{b}$ & 843 & 3.8 & 28.2 \\
\hline
\end{tabular}

${ }^{a}$ Sample maximum temperature $1200 \mathrm{~K}$.

${ }^{b}$ In the temperature range $473-673 \mathrm{~K}$. 
Table 3 Ignition temperature of the investigated powders, as evaluated by a hot-wire technique (air, $0.1 \mathrm{MPa}, 250$ $\pm 50 \mathrm{~K} / \mathrm{s})$

\begin{tabular}{lcc}
\hline \multicolumn{1}{c}{ Powder Id. } & Heating rate, $\mathrm{K} / \mathrm{s}$ & $T_{\mathrm{ign}}, \mathrm{K}$ \\
\hline Al15 & - & - \\
Act-Al15 & $269.2 \pm 8.1$ & $924.2 \pm 22.6$ \\
Act-Al15(10) & $297.1 \pm 28.6$ & $1025.3 \pm 143.2$ \\
Act-Al15(30) & $293.1 \pm 22.3$ & $854.4 \pm 67.1$ \\
\hline ALEX & $281.8 \pm 12.6$ & $864.9 \pm 17.8$ \\
C-ALEX $(10)$ & $287.7 \pm 19.2$ & $828.3 \pm 25.4$ \\
C-ALEX $(15)$ & $279.6 \pm 9.7$ & $772.8 \pm 13.3$ \\
\hline
\end{tabular}

Al15 exhibits a lower metal content than the original Al15. This is due to the milling process impacts, promoting the cracking of the alumina shell covering the particles. $\mathrm{As} \mathrm{Al}$ is exposed to the air environment, it is oxidized and this induces the $C_{\mathrm{Al}}$ reduction. Under relatively high heating rates $(250 \pm 50 \mathrm{~K} / \mathrm{s})$, the ignition of Act-Al15 occurs at $924 \pm 22 \mathrm{~K}$. Under the same operating conditions, the Al15 ignition temperature exceeds the experimental setup measuring range (limited by the use of S-type thermocouples) (see Table 3). The increased reactivity of Act-Al15 with respect to the virgin material is a consequence of the activation process. Particle shape alterations seem the main responsible of the observed behavior, since the absence of $\Delta m_{0}$ in the TG analysis suggests that Act-Al15 is characterized by a relatively low $S_{\mathrm{sp}}$.

The activated powders containing PTFE exhibit more irregular morphology and texture than the Act-Al15 (see Fig. 2). The $C_{\mathrm{Al}}$ of both Act-Al15(10) and Act-Al15(30) is affected by the milling process, with PTFE deposition/inclusion into the activated particles. The $D_{43}$ of the powder batches containing the fluoropolymer is reduced with respect to the Act-Al15 case (see Table 1). This is a possible result of the PTFE friction and wear-properties on the milling process [50]. Under the investigated conditions, Act-Al15(10) and Act-Al15(30) exhibit a monomodal particle size distribution (see Fig. 3). The nonisothermal oxidation data of Act-Al15(10) and Act-Al15(30) are presented in Table 2. Under low heating rates in air, the mechanically activated powders present an initial mass loss (due to the fluoropolymer degradation), followed by an oxidation phase. The values of mass losses for both the fluoropolymer-containing composites suggest the presence of residual PTFE decomposition products on the $\mathrm{Al}$ particle surfaces. This is the possible cause of the delayed $T_{\mathrm{on}, 1}$ of Act-Al15(10) and Act-Al15(30) with respect to Act-Al15.

A similar effect is likely to cause an oxidation onset delay in fluorohydrocarbon-coated ALEX tested under similar operating conditions in a previous study [45]. The oxidation process shows a higher degree of reaction in 
the Act-Al15(10) than in the Act-Al15(30) (see Table 2). After an initial mass loss of $7.1 \%$, the Act-Al15(10) exhibits a mass gain of 7.4\%. The Act-Al15(30) exhibits $\Delta m_{0}=-24.1 \%$, followed by an $\mathrm{Al}$ oxidation yielding $\Delta m_{2}=-21.1 \%$, with a mass gain of $3 \%$. Thus, both the fluoropolymer-containing composites exhibit a lower reactivity than the Act-Al15 under the investigated TG conditions.

The high-heating rate tests show an opposite behavior, with the Act-Al15(30) exhibiting $T_{\text {ign }}=854.4 \pm 67.1 \mathrm{~K}$, and Act-Al15(10) igniting at $1025.3 \pm 143.2 \mathrm{~K}$. Under the investigated conditions, this result may be due to different effects: the PTFE inclusion in the activated particles (as a consequence of the milling process), an Al-PTFE reaction thanks to the reduced diffusion distance, and a Al-PTFE composite reaction with the test environment (in turn triggered by the PTFE thermal decomposition). At the moment, further considerations on the reaction path of the composite are not possible due to diagnostic limitations.

\subsubsection{Coated nano-sized aluminum}

The air-passivated, catechol-coated ALEX is taken as the virgin material for the creation of an innovative oxidizer-fuel composite. An oxidizer coating is realized on the ALEX with AP by a lab-scale procedure developed at SPLab. After the coating deposition, the ALEX + AP rough powder is grinded and sieved to get a particle size $\leq 80 \mu \mathrm{m}$.

Two batches of material are considered in this study. The first one, C-ALEX(10), contains $10 \%$ (wt.) AP. The second one, C-ALEX(15), contains an AP mass fraction of $15 \%$. Under the investigated conditions, the TG of ALEX presents the typical behavior of nano-sized aluminum powders tested in air at low heating rates [47].

As shown in Table 2, after an initial mass loss $\left(\Delta m_{0}=-1.3 \%\right)$ due to desorbed gases, the oxidation proceeds in a two-step process. Before the Al melting, the powder undergoes a mass gain of $27.1 \%$. This first reaction is followed by a second oxidation process yielding $\Delta m_{2}=60.8 \%$. Thus, the overall mass increase of the ALEX powder is $62.1 \%$. The C-ALEX(10) presents a wide particle size distribution, with $D_{43}=6.5 \mu \mathrm{m}$ and a span of 9.06 (see Table 1). Being the measured particle size in the range 0.2 to $80 \mu \mathrm{m}$, the mass-mean diameter is influenced by the larger particles, thus resulting in a micron-sized composite. The $C_{\mathrm{Al}}$ of the powder is $80.5 \pm 2.0 \%$ (wt.) immediately after the production. For the C-ALEX(15), the $C_{\mathrm{Al}}$ results $74.8 \pm 0.1 \%$ (wt.). The TG analysis of the C-ALEX(15) reveals a $\Delta m_{0}=-14.1 \%$ in the temperature range $473-673 \mathrm{~K}$ (see Table 2). This initial mass loss is then followed by an oxidation phase whose onset temperature is the same as for the virgin ALEX powder and yielding $\Delta m_{1}=3.8 \%$. The limiting mass gain achieved by $\mathrm{C}-\operatorname{ALEX}(15)$ is $28.2 \%$ at $T=1223 \mathrm{~K}$. 
Under the investigated operating conditions, the data reported in Table 3 show that at high heating rates in air, the AP-coating can promote a small decrease of the powder $T_{\text {ign }}$ with respect to the virgin ALEX case.

\subsection{Solid Fuel Manufacturing}

The formulation of the HTPB binder used in this study is based on HTPB R45-HTLO (79.2\%(wt.)), dioctyl adipate (13.1\%(wt.)), and isophorone diisocyanate $(7.7 \%$ (wt.)). Dibutyltin diacetate is used as a curing catalyst and is added in excess to the formulation $(0.05 \%$ by mass of the total weight of HTPB and isophorone diisocyanate). The fuel curing level $(-\mathrm{NCO} /-\mathrm{OH})$ is 1.04. Manufacturing is performed by a mechanical mixer. In spite of the use of nanosized additives, in this study, no dispersion protocol was implemented during the manufacturing. This choice is due to the fact that the Al-based composites investigated in this study are in the micron-sized range. The main advantage of additives in this size range is their limited sensitivity (if any) to particle-particle interactions. This simplifies the manufacturing procedure (easing possible largescale applications).

\section{EXPERIMENTAL SETUP AND DATA REDUCTION}

\subsection{Experimental Setup}

The relative ballistic grading of the investigated fuels is performed by burning tests conducted in a two-dimensional (2D) radial microburner. A scheme of the implemented setup is reported in Fig. 4, while a detailed description is given in $[8,29]$. Thanks to its peculiar design, the experimental rig enables a continuous visualization of the head-end section of the tested strand. This is done by the injector head implementation [8] and by a 45 degree mirror reflecting the strand head-end image (see Fig. 1). A digital camera operating with frame rates up to $1000 \mathrm{fps}$ (depending on burning run expected duration and operating conditions) captures the combustion images. The $r_{f}$ data are reduced by a nonintrusive optical technique. The $2 \mathrm{D}$ radial burner is designed to enable a direct control of the test operating conditions $\left(\dot{m}_{\mathrm{ox}}\right.$ and $\left.p_{c}\right)$. Oxidizer mass flow rate and $p_{c}$ can be regulated independently due to the electrovalves acting on the dump line. These servoactuators are driven by a pressure controller whose action enables to reach a quasi-steady $p_{c}$ during the tests [8]. A digital flowmeter provides $\dot{m}_{\text {ox }}$ measurement and control. Strand ignition is achieved by a pyrotechnic primer charge. The latter is ignited by a laser beam impinging on it. Primer charge combustion products, in turn, ignite the tested sample as 


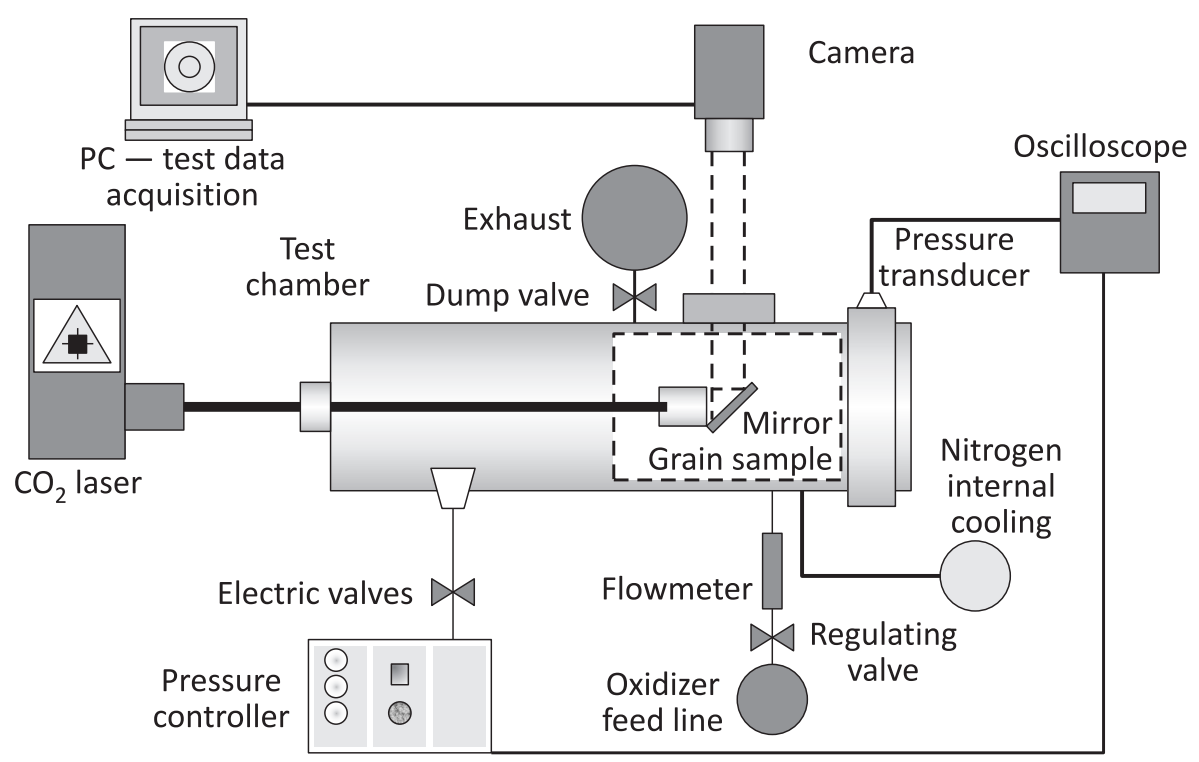

Figure 4 Overview of the 2D radial microburner

they are entrained by oxidizer flow. Tested strands have cylindrical shape, with single central port perforation $\left(D_{0}=4 \mathrm{~mm}\right.$, with $\left.L_{\text {sample }}=30 \mathrm{~mm}\right)$.

\subsection{Regression Rate Data Reduction}

An optical time-resolved technique is used for the $r_{f}$ data reduction [8,29]. The time-resolved technique is based on diameter sampling in time from the recorded combustion video. During the test, the strand head-end is visible and central port diameter is sampled along different radial directions (depending on combustion uniformity). Diameter sampling starts from the time the central port perforation becomes visible (after primer charge ignition). Sampling frequencies up to $10 \mathrm{~Hz}$ are achieved [8]. Usually, two differently oriented local diameters are considered (e.g., vertical and horizontal). Three measurements are taken for each local diameter. The single local diameters sampled at time $t_{i}, D_{j, k}\left(t_{i}\right)$, are evaluated by the different brightness between the flame zone and the regressing surface. Starting from the local measured diameters, $\bar{D}_{i}$ can be defined as

$$
\bar{D}_{i}=\frac{\sum_{j=1}^{2} \sum_{k=1}^{3} D_{j, k}\left(t_{i}\right)}{6}
$$


The sequence of the discrete $\bar{D}_{i}$ defined by Eq. (1) is then fitted to achieve a continuous history of space-averaged diameter evolution in time

$$
\bar{D}(t)-D_{0}=a_{D}\left(t-t_{0}\right)^{n_{D}}, \quad t \geq t_{\text {ign }}>t_{0} .
$$

Diameter $\bar{D}(t)$ is valid for $t \geq t_{\text {ign }}$. The latter is an ad-hoc defined parameter. The $t_{\text {ign }}$ is defined as the time maximizing the data fitting of Eq. (2). A detailed description of the time-resolved technique developed at SPLab is given in $[8,29]$. Solid fuel ballistics can be completely defined starting from Eq. (2), as discussed in [29]. In particular, solid fuel $r_{f}$ and $G_{\text {ox }}$ histories are defined as

$$
\begin{aligned}
r_{f}\left(t \geq t_{\text {ign }}\right) & =\frac{1}{2} \frac{d\left[\bar{D}(t)-D_{0}\right]}{d t}=\frac{1}{2} a_{D} n_{D}\left(t-t_{0}\right)^{n_{D}-1} ; \\
G_{\mathrm{ox}}\left(t \geq t_{\mathrm{ign}}\right) & =\frac{\dot{m}_{\mathrm{ox}}(t)}{\pi \bar{D}(t)^{2} / 4}=\frac{\dot{m}_{\mathrm{ox}}(t)}{\pi\left[D_{0}+a_{D}\left(t-t_{0}\right)^{n_{D}}\right]^{2} / 4} .
\end{aligned}
$$

The fuel mass flow rate can be easily determined starting from the diameter history in time and the regression rate evolution as

$$
\dot{m}_{f}\left(t \geq t_{\text {ign }}\right)=\rho_{f} r_{f}(t) \bar{D}(t) \pi L_{\text {sample }} .
$$

Results achieved by the time-resolved technique are checked comparing them to the corresponding thickness over time (TOT) data in order to gain information on data consistency between different reduction techniques:

$$
\begin{aligned}
r_{f}\left(t_{\text {ign }}\right) & =\frac{1}{2} a_{D} n_{D}\left(t_{\text {ign }}-t_{0}\right)^{n_{D}-1} \stackrel{?}{=} \frac{n_{D}}{2} \frac{\bar{D}\left(t_{\text {ign }}\right)-D_{0}}{t_{\text {ign }}-t_{0}} ; \\
\left\langle r_{f}\left(t_{\text {final }}\right)\right\rangle & =\frac{1}{t_{\text {final }}-t_{\text {ign }}} \int_{t_{\text {ign }}}^{t_{\text {final }}} r_{f}(t) d t \stackrel{?}{=} \frac{1}{2} \frac{\bar{D}\left(t_{\text {final }}\right)-\bar{D}\left(t_{\text {ign }}\right)}{t_{\text {final }}-t_{\text {ign }}} ; \\
\left\langle G_{\text {ox }}\left(t_{\text {final }}\right)\right\rangle & =\frac{1}{t_{\text {final }}-t_{\text {ign }}} \int_{t_{\text {ign }}}^{t_{\text {final }}} G_{\text {ox }}(t) d t \stackrel{?}{=} \frac{\dot{m}_{\text {ox }}}{(\pi / 4)\left\{\left[\bar{D}\left(t_{\text {ign }}\right)+\bar{D}\left(t_{\text {final }}\right)\right] / 2\right\}^{2}} .
\end{aligned}
$$

In the developed time-resolved technique, Eq. (2) is defined for each performed test. In order to summarize results achieved under the same operating conditions for a given fuel, various $\bar{D}(t)$ are collapsed into an ensemble average curve. The latter is defined by a power-law interpolation of time-trends identified applying Eq. (2) to the performed tests. Ensemble curve enables definition of proper error bars for $\bar{D}(t)$ and $r_{f}\left(G_{\text {ox }}\right)$. These are evaluated over the $t$ (or $G_{\text {ox }}$ ) range where at least two of the performed single runs are defined. Over this interval, the error bars are evaluated by confidence intervals centered on the average value resulting from single test diameters at a given time (for Eq. (2)) 
or regression rates at a given $G_{\mathrm{ox}}$ (for Eqs. (3) and (4)). Confidence intervals are evaluated with 95 percent accuracy. In order to compare achieved results with literature data, a power-law approximation of analytical $r_{f}$ vs. $G_{\mathrm{ox}}$ is proposed for each test and for ensemble curves:

$$
r_{f}\left(G_{\mathrm{ox}}\right)=a_{r} G_{\mathrm{ox}}(t)^{n_{r}}, \quad t \geq t_{\mathrm{ign}} .
$$

\section{EXPERIMENTAL RESULTS AND DISCUSSION}

In this section, the experimental results concerning the relative ballistic grading of the HTPB-based fuel formulations loaded with aluminum composites are presented and discussed. The analysis focuses on the effects of the energetic additives on the solid fuel $r_{f}$. Cured HTPB is considered as a baseline for the evaluation of the additive ballistic effect. In particular, the percent $r_{f}$ and $\dot{m}_{f}$ enhancement over the baseline, are defined at $G_{\mathrm{ox}} \geq G_{\mathrm{ox}}\left(t_{\mathrm{ign}}\right)$ as

$$
\begin{aligned}
&\left.\Delta r_{f, \%}\right|_{G_{\mathrm{ox}}=\bar{G}_{\mathrm{ox}}, p_{c}=}=\bar{p}_{c}=\left.100\left(\frac{r_{f, \text { Metal-loaded }}-r_{f, \text { Baseline }}}{r_{f, \text { Baseline }}}\right)\right|_{G_{\mathrm{ox}}=\bar{G}_{\mathrm{oz}}, p_{c}=\bar{p}_{c}} ; \\
&\left.\Delta \dot{m}_{f, \%}\right|_{G_{\mathrm{ox}}=\bar{G}_{\mathrm{ox}}, p_{c}}=\bar{p}_{c} \\
&=\left.100\left(\frac{\dot{m}_{f, \text { Metal-loaded }}-\dot{m}_{f, \text { Baseline }}}{\dot{m}_{f, \text { Baseline }}}\right)\right|_{G_{\mathrm{ox}}=\bar{G}_{\mathrm{ox}}, p_{c}=\bar{p}_{c}} .
\end{aligned}
$$

The solid fuels are tested in GOx, with $p_{c}=1.0 \mathrm{MPa}$. The oxidizer mass flow rate is $5 \mathrm{~g} / \mathrm{s}$ except where otherwise stated. An overview of the tested fuel

Table 4 Theoretical maximum density (TMD), actual (measured) density, and porosity of the investigated fuel formulations. Porosity is defined as the percent difference of TMD and the actual density evaluated with respect to the former

\begin{tabular}{lrcc}
\hline \multicolumn{1}{c}{ Formulation } & $\begin{array}{r}\text { TMD, } \\
\mathrm{kg} / \mathrm{m}^{3}\end{array}$ & $\begin{array}{c}\text { Actual density } \rho, \\
\mathrm{kg} / \mathrm{m}^{3}\end{array}$ & $\begin{array}{c}\text { Porosity, } \\
\text { \% of TMD }\end{array}$ \\
\hline Baseline (HTPB) & 920 & $920 \pm 1.0$ & $<0.1$ \\
HTPB + Al15 & 980 & $980 \pm 1.0$ & $<0.1$ \\
HTPB + Act-Al15 & 980 & $987 \pm 1.0$ & 0.4 \\
HTPB + Act-Al15(10) & 986 & $983 \pm 3.0$ & -0.3 \\
HTPB + Act-Al15(30) & 1006 & $1003 \pm 1.4$ & -0.3 \\
\hline HTPB + ALEX ${ }^{a}$ & 980 & $978 \pm 3.0$ & -0.2 \\
HTPB + C-ALEX $(15)$ & 999 & NA & NA \\
\hline${ }^{a}$ Additive mass fraction is $10 \%$. & &
\end{tabular}


formulations and of their actual densities is given in Table 4. The additive mass fractions of all of the additives but ALEX are defined on the base of equal metal molar content. In the investigated formulations, the additive mass fraction is defined in order to get the same metal molar content as in $\mathrm{HTPB}+10 \%$ (wt.) $\mu \mathrm{Al}$, with the micron-sized aluminum $C_{\mathrm{Al}}=99 \%$ (wt.) (the remainder $1 \%$ (wt.) being alumina). The $r_{f}$ effects of the mechanically activated $\mathrm{Al}$ and $\mathrm{Al}+\mathrm{PTFE}$ composites are introduced first. After this, the ballistic response of the AP-coated nano-sized aluminum is discussed.

\subsection{Mechanically Activated Micron-sized Aluminum}

Under the investigated experimental conditions, the ballistic response of the $\mathrm{HTPB}+\mathrm{Al} 15$ testifies limited influence of the micron-sized additive due to its

Table 5 Percent $r_{f}$ enhancement over the baseline (see Eq. (6)) for the tested fuel formulations loaded with mechanically activated and coated aluminum powders

\begin{tabular}{|c|c|c|c|c|c|}
\hline \multirow{2}{*}{$\begin{array}{c}\text { Fuel } \\
\text { formulation }\end{array}$} & \multicolumn{5}{|c|}{ Oxidizer mass flux, $G_{\text {ox }}, \mathrm{kg} /\left(\mathrm{m}^{2} \mathrm{~s}\right)$} \\
\hline & 150 & 200 & 250 & 300 & 350 \\
\hline HTPB + Al15 & 14.6 & 9.6 & 4.4 & -1.5 & - \\
\hline HTPB + Act-Al15 & 15.2 & 21.5 & 28.4 & 37.4 & - \\
\hline HTPB + Act-Al15(10) & -10.1 & -5.1 & 0.4 & 7.6 & - \\
\hline HTPB + Act-Al15(30) & 0.8 & 7.3 & 14.6 & 24.1 & - \\
\hline $\mathrm{HTPB}^{2} \mathrm{ALEX}^{a, b}$ & 6.0 & 10.5 & 12.6 & 14.9 & 17.7 \\
\hline $\operatorname{HTPB}+\mathrm{C}-\operatorname{ALEX}(15)^{a}$ & 24.9 & 25.4 & 25.9 & 26.5 & 27.2 \\
\hline
\end{tabular}

Table 6 Percent mass burning rate enhancement over the baseline (see Eq. (7)) for the tested fuel formulations loaded with mechanically activated and coated aluminum powders

\begin{tabular}{lccrcc}
\hline \multirow{2}{*}{$\begin{array}{c}\text { Fuel } \\
\text { formulation }\end{array}$} & \multicolumn{5}{c}{ Oxidizer mass flux, $G_{\text {ox }}, \mathrm{kg} /\left(\mathrm{m}^{2} \mathrm{~s}\right)$} \\
\cline { 2 - 6 } & 150 & \multicolumn{1}{c}{200} & \multicolumn{1}{c}{250} & 300 & 350 \\
\hline HTPB + Al15 & 22.1 & 16.7 & 11.2 & 4.88 & - \\
HTPB + Act-Al15 & 22.7 & 29.4 & 36.8 & 46.3 & - \\
HTPB + Act-Al15(10) & -3.07 & 2.28 & 8.2 & 15.9 & - \\
HTPB + Act-Al15(30) & 10.8 & 18.0 & 26.0 & 36.4 & - \\
\hline HTPB + ALEX $^{a, b}$ & 18.3 & 20.6 & 23.1 & 26.1 & 13.5 \\
HTPB + C-ALEX $(15)^{a}$ & 36.9 & 37.5 & 38.1 & 38.8 & 39.3 \\
\hline
\end{tabular}

${ }^{a}$ Tested with oxidizer mass flow rate of $6 \mathrm{~g} / \mathrm{s}$.

${ }^{b}$ Additive mass fraction is $10 \%$. 
Table 7 Relevant parameters and data fitting of the power law approximation of $r_{f}\left(G_{o x}\right)$ (see Eq. (5)). The poor data fitting is due to the marked initial $r_{f}$ values [29]

\begin{tabular}{|c|c|c|c|}
\hline Fuel formulation & $a_{r}, \mathrm{~mm} /\left[\mathrm{kg} /\left(\mathrm{m}^{2} \mathrm{~s}\right)\right]_{r}^{n}$ & $n_{r}$ & Data fitting, $R^{2}$ \\
\hline Baseline (HTPB) & $0.012 \pm 0.001$ & $0.778 \pm 0.003$ & 0.89 \\
\hline HTPB + Al15 & $0.059 \pm 0.001$ & $0.477 \pm 0.001$ & 0.95 \\
\hline HTPB + Act-Al15 & $0.007 \pm^{a}$ & $0.902 \pm 0.003$ & 0.93 \\
\hline HTPB + Act-Al15(10) & $0.005 \pm^{a}$ & $0.908 \pm 0.002$ & 0.95 \\
\hline HTPB + Act-Al15(30) & $0.006 \pm^{a}$ & $0.897 \pm 0.002$ & 0.95 \\
\hline Baseline $(\mathrm{HTPB})^{b}$ & $0.026 \pm^{a}$ & $0.641 \pm 0.002$ & 0.93 \\
\hline $\mathrm{HTPB}+\mathrm{ALEX}^{b, c}$ & $0.017 \pm^{a}$ & $0.730 \pm 0.002$ & 0.95 \\
\hline $\mathrm{HTPB}+\mathrm{C}-\operatorname{ALEX}(15) \mathrm{b}$ & $0.019 \pm^{a}$ & $0.747 \pm 0.002$ & 0.91 \\
\hline
\end{tabular}

${ }^{a}$ Uncertainty is lower than 0.001 .

${ }^{b}$ Tested with oxidizer mass flow rate of $6 \mathrm{~g} / \mathrm{s}$.

${ }^{c}$ Additive mass fraction is $10 \%$.

relatively low $S_{\mathrm{sp}}$. As shown by the data presented in Table 5 , the $\mu$ Al-loaded fuel delivers a $r_{f}$ detriment with respect to the baseline at high $G_{\mathrm{ox}}$, and $\Delta r_{f, \%}$ $=14.6 \%$ at $G_{\mathrm{ox}}=150 \mathrm{~kg} /\left(\mathrm{m}^{2} \mathrm{~s}\right)$. The data shown in Table 6 highlight the increase in the fuel mass burning rate, reaching $22.1 \%$ for $G_{\mathrm{ox}}=150 \mathrm{~kg} /\left(\mathrm{m}^{2} \mathrm{~s}\right)$. The resulting power law approximation of $r_{f}\left(G_{\mathrm{ox}}\right)$ yields $n_{r}=0.477 \pm 0.001$, due to the high radiation heat transfer effects toward the end of the combustion (Table 7).

The ballistic response of HTPB + Act-Al15 is shown in Fig. 5. The ensemble average curve shows instantaneous $r_{f}$ values higher than those of the baseline

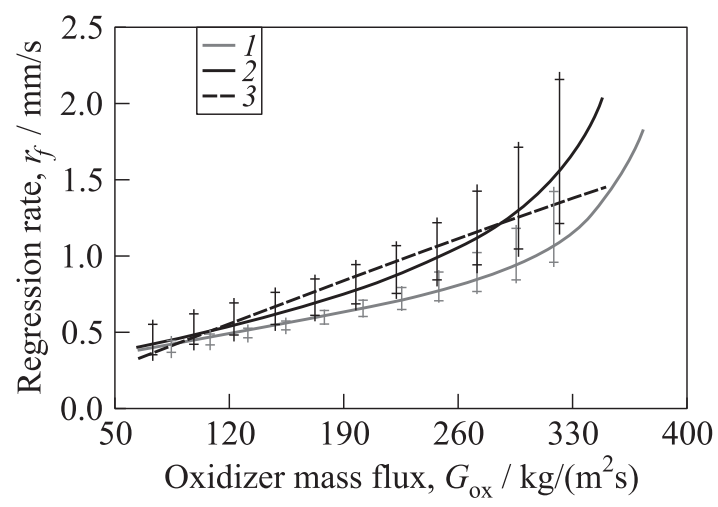

Figure 5 Ballistic response of $\mathrm{HTPB}+\mathrm{Act}-\mathrm{Al15}$, burning in GOx with $p_{c}$ $=1.0 \mathrm{MPa}: 1-$ baseline $(\mathrm{HTPB}) ; 2-\mathrm{HTPB}+$ Act-Al15; and $3-\mathrm{HTPB}+$ ActAl15, Eq. (5) 

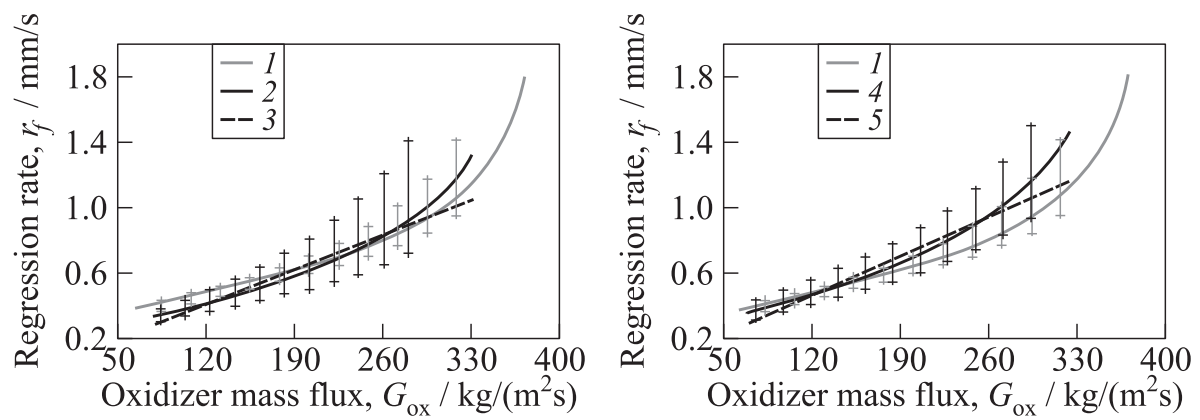

Figure 6 Ballistic response of HTPB loaded with Al + PTFE composites (GOx, $\left.p_{c}=1.0 \mathrm{MPa}\right): 1$ - baseline (HTPB); 2 - HTPB + Act-Al15(10); 3 - HTPB + ActAl15(10), Eq. (5); 4 - HTPB + Act-Al15(30); and 5 - HTPB + Act-Al15(30), Eq. (5)

over the whole investigated $G_{\mathrm{ox}}$-range as testified by the data presented in Tables 5 and 6 . At $G_{\mathrm{ox}}=300 \mathrm{~kg} /\left(\mathrm{m}^{2} \mathrm{~s}\right)$, the $\Delta r_{f, \%}$ of HTPB + Act-Al15 is $37.4 \%$. The percent mass burning rate increase over the baseline ranges from $46.3 \%$ at $G_{\text {ox }}=300 \mathrm{~kg} /\left(\mathrm{m}^{2} \mathrm{~s}\right)$ to $24.7 \%$ at $150 \mathrm{~kg} /\left(\mathrm{m}^{2} \mathrm{~s}\right)$. While the Act-Al15 $T_{\text {ign }}$ is characterized by a reduced data scattering (see Table 3 ), the ensemble $r_{f}\left(G_{\text {ox }}\right)$ of the formulation shows relatively high error bars. This suggests that the bare additive characteristics are uniform, being other effects as the particle-binder interactions responsible for the observed ballistic responses.

The burning behavior of the HTPB loaded with the mechanically activated $\mathrm{Al}+\mathrm{PTFE}$ composites is presented in Fig. 6. As testified by the data reported in Table 6, the HTPB + Act-Al15(10) exhibits no significant $r_{f}$ improvements with respect to the baseline for $G_{\text {ox }}>250 \mathrm{~kg} /\left(\mathrm{m}^{2} \mathrm{~s}\right)$. On the other hand, an $r_{f}$ decrease is achieved in the low oxidizer mass flux region.

For $G_{\mathrm{ox}}=200 \mathrm{~kg} /\left(\mathrm{m}^{2} \mathrm{~s}\right), \Delta r_{f, \%}=-5.1 \%$ and for $G_{\mathrm{ox}}=150 \mathrm{~kg} /\left(\mathrm{m}^{2} \mathrm{~s}\right)$ the percent $r_{f}$ decrease is $10.1 \%$. Thanks to the increased density of HTPB + Act-Al15(10) with respect to the baseline (see Table 4), the fuel mass burning rate is augmented with respect to the HTPB reference until $G_{\text {ox }}=180 \mathrm{~kg} /\left(\mathrm{m}^{2} \mathrm{~s}\right)$. The formulation loaded with Act-Al15(30) offers enhanced performance with respect to both HTPB + Act-Al15(10) and the baseline (see Tables 5 and 6).

For $G_{\mathrm{ox}}=300 \mathrm{~kg} /\left(\mathrm{m}^{2} \mathrm{~s}\right)$, the HTPB + Act-Al15(30) exhibits a $\Delta r_{f, \%}$ $=24.1 \%$, corresponding to a fuel mass burning rate enhancement of $36.4 \%$.

The $\Delta r_{f, \%}$ performance over the baseline decreases during the combustion reaching $0.8 \%$ for $G_{\mathrm{ox}}=150 \mathrm{~kg} /\left(\mathrm{m}^{2} \mathrm{~s}\right)$. Thanks to the fuel formulation density, this performance corresponds to a percent mass burning rate increase of $10.8 \%$. As for the HTPB + Act-Al15, both fuel formulations loaded with Act-Al15(10) and Act-Al15(30) present a relatively high data scattering, possibly related to the additive dispersion and to the fuel manufacturing process. 
The data presented in Table 7 show that the fuel formulations loaded with additives based on Act-Al15 present the same $r_{f}\left(G_{\mathrm{ox}}\right)$ power law dependence. Nevertheless, for the HTPB + Act-Al15, this is the effect of enhanced $r_{f}$ over the baseline in the whole investigated range. The augmented performance of the fuel is related to an increased additive reactivity in the high $G_{\text {ox }}$-range (thanks to a lower $T_{\text {ign }}$ with respect to Al15, see Table 3 ) and to an intense radiation heat transfer in the low $G_{\text {ox }}$ region. It is, moreover, possible that Act-Al15 plays a role in increasing the regressing surface roughness. The HTPB + Act-Al15 behavior in the initial phases of the combustion run can be directly related to the mechanical activation process altering the particle shapes and the alumina shell characteristics (a similar behavior is observed for micron-sized thermites [36]). Under the investigated conditions, the higher the PTFE mass fraction, the stronger the additive effects on the mass burning rate when passing from Act-Al15(10) to Act-Al15(30). Nevertheless, no benefits are achieved by these Al + PTFE composites in the low $G_{\text {ox }}$ region. Neither the additive combustion nor a reaction between the binder and the PTFE decomposition products can provide benefits to the solid fuel $r_{f}$. This behavior contrasts with experimental evidences from the combustion of fluorocarbon and fluorohydrocarbon coated $\mathrm{nAl}$ [47] and requires further investigations.

\subsection{Coated Nano-Sized Aluminum}

The ballistic response of HTPB-based fuels loaded with $\mathrm{nAl}$ and nAl-based composites is presented in Tables $5-7$ and in Fig. 7. These two fuel formulations were tested in GOx, under an oxidizer mass flow rate of $6 \mathrm{~g} / \mathrm{s}$, and

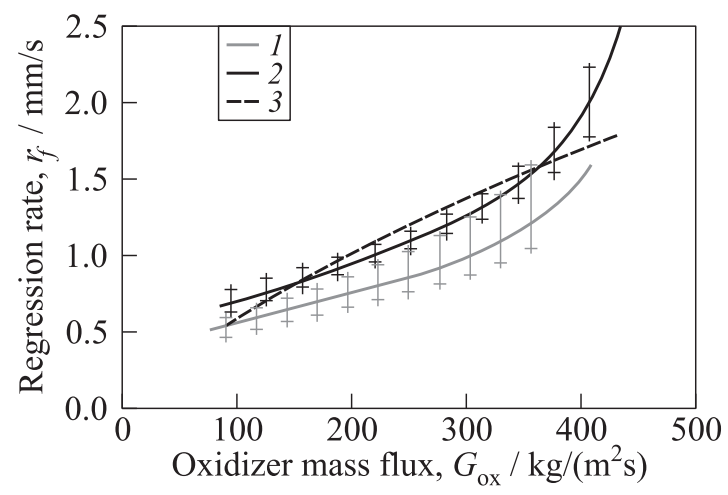

Figure 7 Ballistic response of HTPB loaded with C-ALEX(15) (GOx, $\left.p_{c}=1.0 \mathrm{MPa}\right)$. Tests performed with an initial oxidizer mass flow rate of $6 \mathrm{~g} / \mathrm{s}: 1$ - baseline (HTPB); 2 - HTPB + C-Alex(15); and 3- HTPB + C-Alex(15), Eq. (5) 
$p_{c}=1.0 \mathrm{MPa}$. The relative ballistic grading of the nAl-loaded formulations is performed taking a HTPB baseline burning under the same operating conditions. Both hereby-considered nAl-doped formulations were manufactured without a dedicated dispersion protocol. This was done in order to evaluate the benefits of the C-ALEX(15) over the virgin additive with a standard manufacturing procedure. Under the investigated operating conditions, the absence of a dedicated dispersion protocol for the HTPB + ALEX manufacturing yields a moderate increase of the $r_{f}$ with respect to the baseline. The maximum performance enhancement is achieved in the first phases of the combustion. The ensemble average data exhibit a $\Delta r_{f, \%}=14.9 \%$ at $G_{\text {ox }}=300 \mathrm{~kg} /\left(\mathrm{m}^{2} \mathrm{~s}\right)$, reducing to $6.0 \%$ at $150 \mathrm{~kg} /\left(\mathrm{m}^{2} \mathrm{~s}\right)$. This result is possibly due to two main reasons: the absence of a nanoscale dispersion of the additive and the insurgence of aggregation/agglomeration phenomena in the condensed phase during the combustion [29]. The ballistics of HTPB + C-ALEX(15) exhibits significant improvements over the one of the ALEX100-doped fuel. A mass burning rate percent enhancement $>30 \%$ is achieved in the whole investigated $G_{\mathrm{ox}}$ range. For $G_{\text {ox }}>250 \mathrm{~kg} /\left(\mathrm{m}^{2} \mathrm{~s}\right)$, the error bars of the loaded-fuel ensemble average are partially overlapped to those of the baseline data, while for $G_{\mathrm{ox}} \leq 250 \mathrm{~kg} /\left(\mathrm{m}^{2} \mathrm{~s}\right)$, the uncertainty intervals of the two formulations are distinct. Under the oxidizer mass flux of $300 \mathrm{~kg} /\left(\mathrm{m}^{2} \mathrm{~s}\right)$, the HTPB $+\mathrm{C}-\operatorname{ALEX}(15)$ yields a $\Delta r_{f, \%}=26.5 \%$, corresponding to a fuel mass burning rate percent enhancement of $38.8 \%$. This result shows the attractive features of the proposed coating strategy. The APcoating of ALEX100 yields augmented $r_{f}$ over the baseline, without the implementation of dedicated manufacturing procedures.

\section{CONCLUDING REMARKS AND FUTURE DEVELOPMENTS}

This work deals with the production, preburning, and combustion characterization of aluminum-based energetic additives. Two main families of aluminum composites were considered in the analysis, focusing on their use in HTPB-based hybrid solid fuel compositions. The first additive family is based on the mechanical activation of a spherical 15-micron aluminum (Al15). The second group of additives is based on the use of $\mathrm{nAl}$. The $\mu \mathrm{Al}$ was treated by a low energy ball milling process, with the possible addition of PTFE during the activation. As a result, three different additives were produced: Act-Al15, a mechanically activated variant of the virgin $\mathrm{Al} 15$, and two $\mathrm{Al}+\mathrm{PTFE}$ composites with fluorocarbon content of 10 and $30 \%$ (wt.). The nAl-based composite is a coated variant of an air-passivated ALEX powder. The investigated additive is labeled C-ALEX(15) and has a $15 \%$ (wt.) coating of AP. The strategy based on the use of PTFE and AP aims at realizing energetic additives enhancing the combus- 
tion reactivity of the hybrid fuels by the presence of fuel-oxidizer compositions. The ballistic response of the fuels was investigated under reference conditions $\left(p_{c}=1.0 \mathrm{MPa}, \mathrm{GOx}\right.$ flow $)$ in a $2 \mathrm{D}$-radial burner. Data reduction was performed by a time-resolved approach.

Preburning characterization of the additives was performed by SEM, nonisothermal oxidation (TG), ignition temperature, and $C_{\mathrm{Al}}$ determination tests. The SEM images of the mechanically activated aluminum show the Act-Al15 morphology modification (see Figs. 1 and 2). The milling process yields flakes and particles with irregular textures. The TG runs (air, $10 \mathrm{~K} / \mathrm{min}$ ) evidenced the enhanced reactivity of the Act-Al15. Under the investigated conditions, nonisothermal oxidation runs on this powder yielded a limiting mass gain of $9.1 \%$ at $1223 \mathrm{~K}$, while for the virgin $\mu \mathrm{Al}, \Delta m_{2}=5 \%$. The thermal behavior of the PTFE-containing additives revealed a delayed oxidation onset and a reduced mass gain with respect to the Act-Al15 (see Table 2). The reduced mass gain of the PTFE-composites over the Act-Al15 is related to two main possibilities. First, at low heating rates, the PTFE decomposition and the Al particle oxidation occur as separated reactions. Second, decomposition residuals of the PTFE can hinder the metal oxidation at higher temperatures. In any case, further investigations are needed to fully understand the behavior of the composite. The TG runs performed on the C-ALEX(15) show a higher reactivity of this composite over the $\mu \mathrm{Al}$-based counterpart. The AP-coated additive reaches $\Delta m_{2}=28.2 \%$. Considering the coating degradation, the overall mass gain results in $42.3 \%$ (see Table 2). The data presented in Table 3 show the result of the ignition temperature tests performed with heating rate of $250 \pm 50 \mathrm{~K}$. Under the investigated conditions, Act-Al15(30) exhibits a marked reactivity, with ignition occurring at $854.4 \pm 67.1 \mathrm{~K}$. Only C-ALEX(15) yields better results, with $T_{\text {ign }}=772.8 \pm 13.3 \mathrm{~K}$, while the Act-Al15(10) ignites at $1025.3 \pm 143.24 \mathrm{~K}$. The latter result is influenced by two different effects. The first one is the reduced impact effects during the milling process due to the presence of a relatively soft material (i.e., PTFE) (see Fig. 2). The second one is the limited fluoropolymer dispersion in the final product, low oxidizing contribution to the composite ignition. While for Act-Al15(30) the PTFE dispersion and mass fraction promotes the reactivity limiting the negative effects of the PTFE softness, this does not happen for Act-Al15(10). The mechanically activated Al-based additives exhibit interesting performance in terms of the solid fuel $r_{f}$ and mass burning rate enhancement. The result presented in Tables 6 and 7 show that Act-Al15(30) yields a stronger effect on the fuel mass burning rate than Act-Al15(10). This highlights the possible benefits of the PTFE-addition to the Al mechanical activation process. Act-Al15 shows a marked effect on the $r_{f}$ enhancement over the baseline at high oxidizer mass fluxes, yielding $\Delta r_{f, \%}=37.4 \%$ at $300 \mathrm{~kg} /\left(\mathrm{m}^{2} \mathrm{~s}\right)$. The result is only partially reduced by the $G_{\text {ox }}$ decrease. The combustion of HTPB + C-ALEX(15) showed the benefits of AP-coated nAl on the ballistic response of the solid fuel. The composite has a relatively large particle size 
$\left(D_{43}=6.7 \mu \mathrm{m}\right) ;$ nevertheless, it provides $\Delta r_{f, \%}>20 \%$ over the whole investigated $G_{\text {ox }}$-range without requiring a dedicated fuel manufacturing/casting procedure. According to the experimental $r_{f}$ data, the AP-coating seems to hinder the aggregation/agglomeration processes in the fuel condensed phase, thus limiting the $G_{\text {ox }}$-dependence observed in nAl-doped fuels burning under similar operating conditions $[29,39,47]$.

Recommended future steps of this work should focus on a detailed investigation of the influence of the effects of process parameters on the characteristics of the final mechanical and chemical activated composites (e.g., Al and PTFE initial particle sizes, milling time and conditions, techniques for coating deposition). At the same time, an assessment of the possible end-user issues due to the composite nature of the powders should be performed. Focusing on fluoropolymer-containing additives, the path of the Al-PTFE reaction should be analyzed in details. In light of the C-ALEX(15) benefits to the HTPB ballistic response, the possible influence of the coating on the final particle size and active metal content stability in time should be investigated to increase the powder $r_{f}$-effect while avoiding/limiting possible additive ageing and degradation.

\section{REFERENCES}

1. Altman, D., and A. Holzman. 2008. Overview and history of hybrid rocket propulsion. Fundamentals of hybrid rocket combustion and propulsion. Eds. M. J. Chiaverini and K. K. Kuo. AIAA progress in astronautics and aeronautics ser. Vol. 218. Ch. 1. P. 1-36.

2. Chiaverini, M. J. 2007. Review of solid fuel regression rate behavior in classical and non-classical hybrid rocket motors. Fundamentals of hybrid rocket combustion and propulsion. Eds. M. J. Chiaverini and K. K. Kuo. AIAA progress in astronautics and aeronautics ser. Vol. 218. Ch. 2. P. 37-125.

3. Marxman, G. A., and M. Gilbert. 1963. Turbulent boundary layer combustion in the hybrid rocket. 9th Symposium (International) on Combustion. New York, NY: Academic Press, Inc. 371-383.

4. Marxman, G. A. 1967. Boundary layer combustion in propulsion. 11th Symposium (International) on Combustion Proceedings. Pittsburg, PA: The Combustion Institute. 269-289.

5. Marxman, G. A., and C. E. Wooldridge. 1968. Research on the combustion mechanism of hybrid rockets. Advances in tactical rocket propulsion: AGARD Conference Proceedings. Ed. S. S. Penner. 1:421-477.

6. Risha, G. A., G. C. Harting, K. K. Kuo, A. Peretz, D. E. Koch, H. S. Jones, and J. P. Arves. 1998. Pyrolysis and combustion of solid fuels in various oxidizing environments. AIAA Paper No. 1998-3184-556.

7. Chiaverini, M. J., G. C. Harting, Y. C. Lu, K. K. Kuo, A. Peretz, S. Jones, B. Wygle, and J.P. Arves. 1999. Pyrolysis behavior of hybrid rocket solid fuels under rapid heating conditions. J. Propul. Power 15(6):888-895. 
8. Paravan, C., M. Manzoni, G. Rambaldi, and L. T. DeLuca. 2013. Analysis of quasisteady and transient burning of hybrid fuels in a laboratory-scale burner by an optical technique. Int. J. Energetic Materials Chemical Propulsion 12(5):385-410. doi: 10.1615/IntJEnergeticMaterialsChemProp.20130.

9. Risha, G. A., B. J. Evans, E. Boyer, and K. K. Kuo. 2007. Metals, energetic additives and special binders used in solid fuels for hybrid rockets. Fundamentals of hybrid rocket combustion and propulsion. Eds. M. J. Chiaverini and K. K. Kuo. AIAA progress in astronautics and aeronautics ser. Vol. 218. Ch. 10. P. 413-456.

10. Karabeyoglu, M. A., D. Altman, and B. J. Cantwell. 2002. Combustion of liquefying hybrid propellants: Part 1, general theory. J. Propul. Power 18(3):610-620.

11. Karabeyoglu, M. A., and B. J. Cantwell. 2002. Combustion of liquefying hybrid propellants: Part 2, stability of liquid films. J. Propul. Power 18(3):621-630.

12. Knuth, W. A., M. J. Chiaverini, J. A. Sauer, and D. J. Gramer. 2002. Solid-fuel regression rate behavior of vortex hybrid rocket engines. J. Propul. Power 18(3):600609.

13. Shin, K. H., C. Lee, and S. Y. Chang. 2005. The enhancement of regression rate of hybrid rocket fuel by various methods. AIAA Paper No. 2005-0359.

14. Kim, S., J. Lee, H. Moon, H. Sung, J. Kim, and J. Cho. 2010. Effect of paraffinLDPE blended fuel in hybrid rocket motor. AIAA Paper No. 2010-7031.

15. Calabro, M., L. T. DeLuca, L. Galfetti, and C. Perut. 2007. Advanced hybrid solid fuels. 58th Astronautical Congress (International). Hyderabad, India. IAC07-C4.2.09.

16. George, P., S. Krishnan, P. M. Varkey, M. Ravindran, and L. Ramachandran. 1998. Fuel regression rate enhancement studies in HTPB/GOx hybrid rocket motors. AIAA Paper No. A98-35064.

17. Frederick, R. A., J. J. Whitehead, L. R. Knox, and M. D. Moser. 2007. Regression rates study of mixed hybrid propellants. J. Propul. Power 23(1):175-180.

18. Osmon, R. V. 1966. An experimental investigation of a lithium aluminum hydridehydrogen peroxide hybrid rocket. Aerospace chemical engineering. Ed. D. J. Simkin. Chemical Engineering Progress Symposium ser. American Institute of Chemical Engineers. 62(21):92-102.

19. Sarner, S. F. 1966. Propellant chemistry. Reinhold Publishing Corp. 350 p.

20. Maggi, F., G. Gariani, L. Galfetti, and L. T. DeLuca. 2012. Theoretical analysis of hydrides in solid and hybrid rocket propulsion. Int. J. Hydrogen Energ. 37:17601769.

21. Humble, R. W. 2000. Fuel performance enhancements for hybrid rockets. AIAA Paper No. 2000-3437.

22. Larson, B. D., E. Boyer, T. Wachs, K. K. Kuo, J. D. DeSain, T. J. Curtiss, and B. B. Brady. 2011. Characterization of the performance of paraffin $/ \mathrm{LiAlH}_{4}$ solid fuels in a hybrid rocket system. AIAA Paper No. 2011-5822.

23. DeSain, J. D., T. J. Curtiss, K. Metzler, and B. Brady. 2011. Testing hypergolic ignition of paraffin wax $/ \mathrm{LiAlH}_{4}$ mixtures. AIAA Paper No. 2011-6636.

24. Schoenitz, M., B. Patel, O. Agboh, and E. L. Dreizin. 2010. Oxidation of aluminum powders at high heating rates. Thermochim. Acta 507-508:115-122. 
25. Hahma, A. 2004. Method of improving the burn-rate and ignitability of aluminium fuel particles and aluminium fuel so modified. WO Patent WO/2004/048,295. Available at: http://patentscope.wipo.int/search/en/WO200404829 (accessed February 8, 2018).

26. Hahma, A., A. Gany, and K. Palovuori. 2006. Combustion of activated aluminum. Combust. Flame 145(3):464-480.

27. Paravan, C., A. Reina, A. Sossi, M. Manzoni, G. Massini, G. Rambaldi, E. Duranti, A. Adami, E. Seletti, and L. T. DeLuca. 2012. Time-resolved regression rate of innovative solid fuel formulations. Progress in propulsion physics. Eds. L. T. DeLuca, C. Bonnal, O. Haidn, and S. M. Frolov. Moscow: TORUS PRESS. 4:75-98.

28. Maggi, F., S. Dossi, C. Paravan, L. T. DeLuca, and M. Liljedahl. 2013. Activated aluminum for space propulsion. Powder Technol. 270(A):46-52.

29. Paravan, C. 2012. Ballistics of innovative solid fuel formulations for hybrid rocket engines. Politecnico di Milano, Department of Aerospace Science and Technology. PhD Diss.

30. Kitagawa, K., P. Joseph, V. Novozhilov, and T. Shimada. 2012. Characteristics of chemically modified and nanocomposite polymers as novel fuels for hybrid rocket propulsion. Int. J. Energetic Materials Chemical Propulsion 11(6):549-566.

31. Air Force SBIR/STTIR. 2012. Magnesium boron composites developed as a new fuel for propulsion and combustion. Available at http://www.afsbirsttr.com/ Publications/Documents/Innovation-050610-MACHI-OSD05-T001.pdf (accessed June 2015).

32. Sippel, T., S. F. Son, and L. J. Groven. 2013. Altering reactivity of aluminum with selective inclusion of polytetrafluoroethylene through mechanical activation. Propell. Explos. Pyrot. 38(2):286-295.

33. Dossi, S. 2014. Mechanically activated Al fuels for high performance solid rocket propellants. Politecnico di Milano, Department of Aerospace Science and Technology. PhD Diss.

34. Barseghyana, S. H., and Y. Sakka. Mechanochemical activation of aluminum powder and synthesis of alumina based ceramic composites. Ceram. Int. 39(7):81418146 .

35. Gromov, A. A., A. Ilyin, U. Forter-Barth, and U. Teipel. 2006. Characterization of aluminum powders: II. Aluminum nanopowders passivated by non-inert coatings. Propell. Explos. Pyrot. 31(5):401-409.

36. Pantoya, M.L., and J. J. Granier. 2005. Combustion behavior of highly energetic thermites: Nano- versus micron-composites. Propell. Explos. Pyrot. 30(1):53-62.

37. Risha, G. A., B. Evans, E. Boyer, R. B. Wehrman, and K. K. Kuo. 2003. Nano-sized aluminum, and boron-based solid fuel characterization in a hybrid rocket engine. AIAA Paper No. 2003-4593.

38. Evans, B., N.A. Favorito, E. Boyer, and K. K. Kuo. 2004. Characterization of solid fuel burning rates in an X-ray transparent hybrid rocket engine. AIAA Paper No. 2004-3821.

39. Sossi, A., E. Duranti, M. Manzoni, C. Paravan, L. T. DeLuca, A. B. Vorozhtsov, M. I. Lerner, N. G. Rodkevich, A. A. Gromov, and N. Savin. 2013. Combustion of 
HTPB-based solid fuels loaded with coated nanoaluminum. Combust. Sci. Technol. 185(1):17-36.

40. Reina, A. 2013. Nano-metal fuels for hybrid and solid propulsion. Politecnico di Milano, Department of Aerospace Sciences and Technologies. PhD Thesis.

41. Kwok, Q. S. M., R.C. Fouchard, A. M. Turcotte, P. D. Lightfoot, R. Bowes, and D. E. G. Jones. 2002. Characterization of aluminum nanopowder compositions. Propell. Explos. Pyrot. 27:229-240.

42. Cliff, M., F. Tepper, and V. Lisetsky. 2001. Ageing characteristics of ALEX ${ }^{\mathrm{TM}}$ nanosized aluminum. AIAA Paper No. 2001-3287.

43. Kivity, M., G. Hartman, and A. M. Achlama. 2005. Aging of HTPB propellant. AIAA Paper No. 2005-3802.

44. Cerri, S., M. A. Bohn, K. Menke, and L. Galfetti. 2009. Ageing behavior of HTPBbased rocket propellant formulations. Cent. Eur. J. Energ. Mat. 6(2):149-165.

45. Sossi, A., E. Duranti, C. Paravan, L. T. DeLuca, A. B. Vorozhtsov, A. A. Gromov, Y. I. Pautova, M. I. Lerner, and N. G. Rodkevich. 2013. Non-isothermal oxidation of aluminum nanopowder coated by hydrocarbons and fluorohydrocarbons. Appl. Surf. Sci. 271:337-343.

46. DeLuca, L. T., L. Galfetti, F. Maggi, G. Colombo, C. Paravan, A. Reina, S. Dossi, M. Fassina, and A. Sossi. 2014. Characterization and combustion of aluminum nanopowders in energetic systems. Metal nanopowders: Production, characterization, and energetic applications. Eds. A. A. Gromov and U. Teipel. John Wiley \& Sons. 301-410. doi: 10.1002/9783527680696.ch12.

47. Ilyin, A., A. Gromov, V. An, F. Faubert, C. de Izarra, A. Espagnacq, and L. Brunet. 2002. Characterization of aluminum powders I. Parameters of reactivity of aluminum powders. Propell. Explos. Pyrot. 27(6):361-364.

48. Maggi, F. 2014. Curing viscosity of HTPB-based binder embedding micro- and nano-aluminum particles. Propell. Explos. Pyrot. 39(5):755-760.

49. Resodyn ${ }^{\mathrm{TM}}$ Acoustic Mixtures. 2015. LabRAM Mixer. Available at: http://www. resodynmixers.com/products/labram/ (accessed February 9, 2018).

50. Biswas, S. W., and K. Vijaian. 1992. Friction and wear of PTFE - a review. Wear 158(1):193-211. 